\title{
Umbilical hidradenitis suppurativa symptoms: a case series and review of the literature
}

\author{
Rune Kjærsgaard Andersen ${ }^{1,2} \bowtie$, Gregor Borut Ernst Jemec ${ }^{1,2}$, Ditte Marie Saunte ${ }^{1,2}$ \\ ${ }^{1}$ Department of Dermatology, Zealand University Hospital, Roskilde, Denmark. ${ }^{2}$ Health Sciences Faculty, University of Copenhagen, Copenhagen, \\ Denmark.
}

\begin{abstract}
Introduction: Umbilical erythema, itching, pain, and suppuration among hidradenitis suppurativa (HS) patients form a group of symptoms that is not described in the medical literature.

Methods: A review of the medical literature combined with a case series of patients experiencing umbilical symptoms in relation to HS. These were collected among 348 HS patients connected to the Department of Dermatology at Zealand University Hospital, Roskilde, Denmark, and members of the Danish HS Association's Facebook page (Patientforeningen HS Danmark), who were asked to complete a questionnaire to better describe their symptoms.

Results: Umbilical symptoms among HS patients are previously undescribed in the medical literature. Among the outpatient clinic's patients, $7.1 \%$ (24/348) experienced umbilical symptoms, and for the Facebook group the number was $10.3 \%$ (28/272). Twenty-eight patients agreed to answer the questionnaire. Three-quarters of them experienced not only itching and erythema, but also malodorous and/or bloody umbilical discharge.

Conclusions: The description of discharge symptoms experienced by many patients is similar to the description of symptoms of an umbilical pilonidal sinus (UPS). This is a condition with a morphology reminiscent to that of HS because it is defined by sinus tract formation triggered by hair penetrating the umbilical skin. UPS could be an explanation for umbilical HS symptom.
\end{abstract}

Keywords: hidradenitis suppurativa, umbilical suppuration, umbilical discharge, umbilical pilonidal sinus

Received: 12 September 2019| Returned for modification: 14 November 2019|Accepted: 3 December 2019

\section{Introduction}

Hidradenitis suppurativa (HS) is a chronic skin disease of the pilosebaceous unit in which boil formation and subsequent scarring cause physical impairment and stigmatization (1). The disease is linked to obesity and smoking (2), but the underlying cause of the disease, including the possible role of bacteria and biofilm, remains unclear (3). Advancements in treatment options (4) during the last decade have had a positive effect on patients' quality of life $(5,6)$. Even so, many aspects of HS remain unexplored. During consultations with HS patients in our outpatient clinic, it became apparent that umbilical symptoms (Fig. 1a-c) have not yet received proper attention within the framework of HS symptomatology. The phenomenon itself-to the best knowledge of the authors-has not been described in the literature, and its possible clinical significance is unexplored. We therefore decided to review the literature and investigate the symptoms in our patient population.

\section{Methods}

\section{Literature review}

A literature review was performed using the string ("umbilicus" OR "navel” OR "belly button" OR "bellybutton") AND ("hidradenitis" OR "inverse acne" OR acne inver*) in the PubMed, Ovid, and Web of Science databases.

\section{Case series}

The cases were initially collected through the outpatient clinic but were then expanded by contacting the president of the Danish HS Association and by directly contacting HS patients willing to participate in research (both modes of contact are described in detail below). This was done to gain a rough sense of the prevalence of umbilical HS symptoms.

\section{Patient surveys}

The president of the Danish HS Association relayed a question to the association's Facebook forum, which has 1,299 members. A simple poll was created asking whether they had experienced umbilical symptoms (erythema, stinging/burning sensations, pain, or suppuration) in relation to or just prior to an HS flare. The members could then answer "yes" if they had experienced symptoms and "no" if they had not.

\section{Umbilical questionnaire}

Three hundred thirty-eight patients that gave previous written consent to be contacted for research on HS were asked if they had any umbilical symptoms. A positive response was followed up by a questionnaire that contained standard descriptive questions, questions pertaining to umbilical symptoms and effects of possible treatment, and finally a free-response section, where patients could describe their general or HS-specific medical history.

\section{Statistics}

Statistical differences between the groups were analyzed using Pearson's chi-squared test. All the data were entered into Excel, and 
analysis was performed in R-3.3.1 for Windows (GNU General Public License). The criterion for statistical significance was $p<0.05$.

\section{Ethical approval}

Under Danish law, questionnaire-based studies do not require prior ethical approval, and informed consent is per definition given by way of participation. The study followed the guidelines as stipulated in the 1983 Revised Declaration of Helsinki. Patients provided oral and written consent for publication of the photos featured in figure 1.

\section{Results}

\section{Literature review}

The literature review resulted in four hits. Upon full text examination, it became apparent that all mentions of HS and the umbilicus concerned the risk of HS lesions in the area immediately surrounding the umbilicus. None mentioned an occurrence of HS in the umbilicus or presented cases of HS patients with umbilical symptoms. The only specific example of umbilical symptoms in an HS patient came not from scientific literature, but from a simple Google search in which a patient on an HS support website conveyed her story of umbilical symptoms as the primary manifestation of her HS (7).

\section{Patient surveys}

Of the 1,299 members in the Danish HS Facebook group, 272 members $(20.9 \%)$ took part in the poll. Of those, 28 (10.3\%) answered that they did experience either erythema, suppuration, itching, or a stinging sensation of their umbilicus either preceding or at the time of a HS flare. Of the 348 HS patients that had previously allowed us to contact them, we were able to contact 338 , and of those $24(7.1 \%)$ replied that they have or had experienced umbilical symptoms. Of those 24 patients, 15 (62.5\%) agreed to complete the questionnaire. We had previously uncovered four cases through our outpatient clinic, leaving us with 19 cases for this case series.

\section{Umbilical questionnaire}

The 19 cases are listed in Table 1. Briefly, 52.6\% (10/19) of the HS patients experienced umbilical symptoms in relation to HS flares, $73.7 \%(14 / 19)$ of the patients experienced malodourous or bloody discharge from the umbilicus, and the remaining $26.3 \%(5 / 19)$ experienced erythema and itching but no discharge. Forty-two percent (8/19) had never received treatment for their umbilical symptoms. Of those that had tried either antimycotic or antibiotic treatment, 45.5\% (5/11) did not experience any effect.

Among those that did not receive treatment for their umbilical symptoms, many explained that they had never informed their dermatologist of the symptoms because they had never specifically been asked about umbilical symptoms.

Separating the patients into two groups (Table 2) based on the presence of umbilical discharge, we found that the groups did not differ with regard to the prevalence of obesity, rheumatoid arthritis (RA), psoriasis (PSO), inflammatory bowel disease (IBD), or manifestation of symptoms in relation to HS flares $(p=0.14$ for obesity, $p>0.20$ for all others).

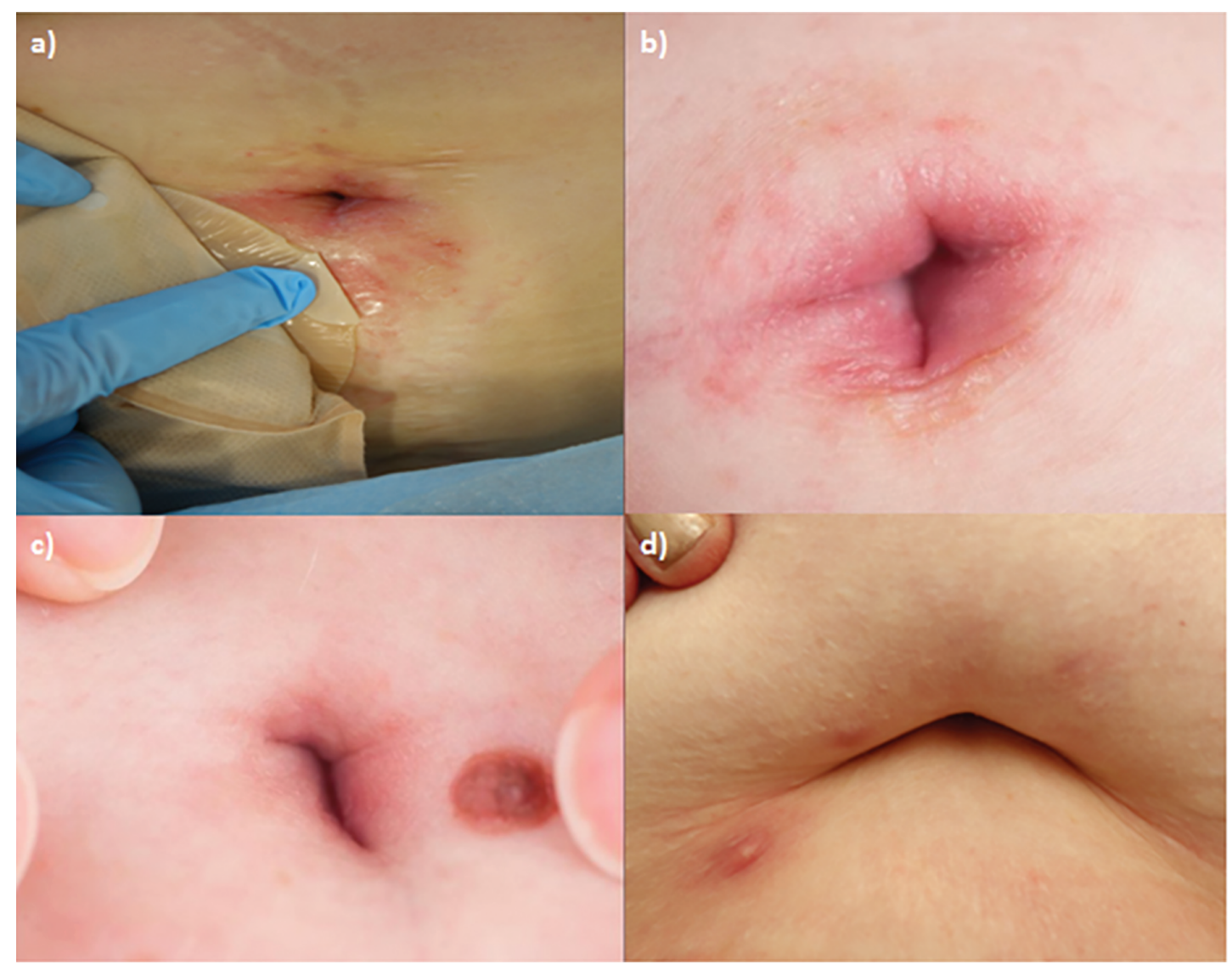

Figure 1 | Examples of umbilical symptoms experienced by hidradenitis supurativa (HS) patients in our clinic: a) umbilical erythema next to stoma as visible at consultation in the late fall of 2018; b) umbilical erythema as visible during a HS flare in 2014; c) mild umbilical erythema as visible at the time of referral in 2014; d) inactive umbilicus as of January 2018 showing surrounding lesional skin. 
Table 1 | Case series of the 19 cases with listed umbilical symptoms, comorbidities, and dispositions.

\begin{tabular}{|c|c|c|c|c|c|c|c|c|c|c|c|}
\hline \multicolumn{5}{|c|}{ Umbilical cases } & \multicolumn{3}{|r|}{ Comorbidities } & \multicolumn{4}{|r|}{ Dispositions } \\
\hline Case & HS & $\begin{array}{l}\text { Umbilical } \\
\text { symptoms } \\
\text { only during } \\
\text { HS flares }\end{array}$ & $\begin{array}{l}\text { Malodorous } \\
\text { or bloody } \\
\text { discharge }\end{array}$ & $\begin{array}{c}\text { Effect of topical } \\
\text { treatment } \\
\text { (antimycotic, } \\
\text { antibiotic, etc.) }\end{array}$ & PSO & IBD & Other & HS & PSO & IBD & Other \\
\hline 1 & + & + & - & + & - & + & - & NA & NA & NA & NA \\
\hline 2 & + & + & - & - & - & - & - & - & + & - & RA \\
\hline 3 & + & + & - & - & - & $(+)$ & - & + & + & - & - \\
\hline 4 & + & - & - & - & - & - & Obesity, Sjögren, RA & - & + & + & - \\
\hline 5 & + & - & + & - & - & $(+)$ & Bipolar, Pso A & + & - & - & - \\
\hline 6 & + & + & + & $(+)$ & - & $(+)$ & Obesity & + & - & - & - \\
\hline 7 & + & - & + & - & - & - & Hypothyroidism, obesity & - & + & - & Acne, PTSD, RA, heart failure \\
\hline 8 & + & - & + & Not received & + & + & $\begin{array}{c}\text { Pso A, steatosis, chronic } \\
\text { pancreatitis, osteoporosis, } \\
\text { hypertension, proliferative } \\
\text { glomerulonephritis, PCOS, } \\
\text { [hypothyroidism], [alopecia } \\
\text { areata] }\end{array}$ & - & $(+)$ & $(+)$ & Alopecia areata, (Pso A) \\
\hline 9 & + & + & + & Not received & + & - & Hypertension & - & + & - & Hypertension, gout, RA \\
\hline 10 & + & - & + & Not received & - & - & $\begin{array}{l}\text { Hypertension, severe } \\
\text { obesity, PCOS, depression, } \\
\text { anxiety, umbilical hernia }\end{array}$ & - & - & - & Diabetes, cardiac disease \\
\hline 11 & + & - & + & Not received & - & - & $\begin{array}{c}\text { Obesity, hypothyroidism, } \\
\text { (RA) }\end{array}$ & + & - & - & $\begin{array}{c}\text { Cardiac disease, RA, acne, } \\
\text { (unspecified psychiatric } \\
\text { disease) }\end{array}$ \\
\hline 12 & + & - & - & Not received & + & - & $\begin{array}{l}\text { RA, diabetes, obesity, } \\
\text { hypertension }\end{array}$ & + & - & - & $\begin{array}{c}\text { Gout, hypertension, coronary } \\
\text { disease }\end{array}$ \\
\hline 13 & + & - & + & + & - & - & Obesity & - & - & - & - \\
\hline 14 & + & + & + & Not received & - & - & Depression & - & - & - & Skin and psychiatric disorders \\
\hline 15 & + & + & + & + & - & - & Obesity & - & - & - & $\begin{array}{c}\text { Lymphoma, rosacea, } \\
\text { sarcoidosis, AMI, } \\
\text { hypertension, abdominal } \\
\text { aorta aneurism, umbilical and } \\
\text { inguinal hernias }\end{array}$ \\
\hline 16 & + & - & + & Not received & $(+)$ & - & $\begin{array}{c}\text { Hypertension, severe } \\
\text { obesity, depression, } \\
\text { diabetes, (RA), (PSO), } \\
\text { (irritable bowel syndrome) }\end{array}$ & + & - & - & $\begin{array}{l}\text { Joint, coronary, and } \\
\text { hormonal diseases }\end{array}$ \\
\hline 17 & + & + & + & + & + & + & Obesity & + & - & $(+)$ & RA \\
\hline 18 & + & + & + & + & - & - & Obesity & + & - & - & $\begin{array}{l}\text { Obesity, colon cancer, } \\
\text { lung cancer }\end{array}$ \\
\hline 19 & + & + & + & Not received & - & + & $\begin{array}{c}\text { RA, DM2, obesity, } \\
\text { hypertension, artificial } \\
\text { cardiac valve }\end{array}$ & + & - & - & $\begin{array}{l}\text { DM, thrombosis, AMI, } \\
\text { stroke, glioblastoma }\end{array}$ \\
\hline Total & 19 & $10 / 19$ & $14 / 19$ & $\begin{array}{l}6 / 11 \\
\text { NA } 8\end{array}$ & $5 / 19$ & $7 / 19$ & $\begin{array}{l}\text { Have either PSO or IBD: } \\
10 / 19\end{array}$ & $9 / 19$ & $6 / 19$ & $3 / 19$ & $\begin{array}{c}\text { Have either disposition for/ } \\
\text { comorbidity of IBD/PSO: } \\
13 / 19\end{array}$ \\
\hline
\end{tabular}

$+=$ yes, $-=$ no, $\mathrm{HS}=$ hidradenitis suppurativa, $\mathrm{PSO}=$ psoriasis, IBD = inflammatory bowel disease, $\mathrm{RA}=$ rheumatoid arthritis, Pso A = psoriatic arthritis, DM2 $=$ diabetes mellitus type $2, \mathrm{AMI}=$ acute myocardial infarction, $\mathrm{PCOS}=$ polycystic ovary syndrome, PTSD = posttraumatic stress disorded, $\mathrm{NA}=$ not available, $0=$ symptoms compatible with disease but no diagnosis, or uncertainty of the result, [] = diagnosis a patient previously had but no longer suffers from.

Table 2 | Comparisons between the two groups separated by the experience of umbilical discharge.

\begin{tabular}{|c|c|c|c|}
\hline Variables & Patients with umbilical discharge, $n(\%)$ & Patients without umbilical discharge, $n(\%)$ & $p$-value \\
\hline Total & $14(73.7)$ & $5(26.3)$ & \\
\hline Symptoms manifest during HS flares & $7(50.0)$ & $3(60.0)$ & 1 \\
\hline PSO diagnosis/symptoms & $4(28.6)$ & $1(20.0)$ & 1 \\
\hline PSO symptoms and/or familial disposition & $5(35.7)$ & $4(80.0)$ & 0.24 \\
\hline IBD diagnosis/symptoms & $5(35.7)$ & $2(40.0)$ & 1 \\
\hline IBD symptoms and/or familial disposition & $8(57.1)$ & $3(60.0)$ & 0.68 \\
\hline RA diagnosis/symptoms & $3(21.4)$ & $2(40.0)$ & 0.83 \\
\hline BMI matching obesity diagnosis & $10(71.4)$ & $1(20.0)$ & 0.14 \\
\hline Received topical treatment & $7(50.0)$ & $4(80.0)$ & 0.51 \\
\hline Effect of topical treatment & $5(71.3)$ & $1(25.0)$ & 0.39 \\
\hline
\end{tabular}

Basic descriptive analysis of HS patients experiencing umbilical symptoms in the form of umbilical discharge and those that do not. PSO $=$ psoriasis, IBD = inflammatory bowel disease, $\mathrm{RA}=$ rheumatoid arthritis, $\mathrm{BMI}=$ body mass index; $p$-values are calculated with Pearson's chi-squared test.

\section{Discussion}

Some patients with HS complain of umbilical symptoms. Currently the literature only describes the possibility of an HS lesion in the area immediately surrounding the umbilicus and does not mention actual umbilical symptoms among HS patients. We found the prevalence of umbilical symptoms to be 7 to $10 \%$ based on two simple surveys. The underlying mechanism remains speculative.

Possible explanations for suppuration of the umbilicus provided by the medical literature include a persistent urachal sinus 
(8), an umbolith (umbilical stone) formed by keratin and sebum deposits (9), and umbilical pilonidal sinus (UPS) (10). All are rare conditions, and thus any relationship with HS is unexplored.

UPS is defined by painful purulent, malodorous, and occasionally bloody discharge (10), caused by a sinus tract formation triggered by a tuft of hair penetrating the umbilical skin. The association between pilonidal sinus and HS was mentioned as early as 1949, when Jackman and McQuarrie (11) stated that HS is commonly confused with pilonidal sinus and vice-versa. In fact, cases of recurrent pilonidal sinus or anal fistulas could in part be explained as cases of HS. Today the association between pilonidal sinus and HS is widely established (11-13), and they share the same basic pathogenesis (12). The disease pathology is reminiscent to that of HS, in which enlargement of the deepest parts of the hair follicle is believed to lead to sinus tract formation, as visualized by ultrasound, where dermal and subcutaneous sinus tracts are connected to the base of regional hair follicles (14).

However, alternative explanations must also be considered. Many patients either had a genetic disposition to or showed symptoms of PSO and/or IBD, both of which could explain the symptoms. However, these would rarely be the cause of purulent, malodorous, and occasionally bloody umbilical discharge as experienced by a majority of this study's HS patients. Moreover, whereas the frequency of PSO and IBD were considerably higher in our groups than in the background population, we did not find significant differences in prevalence between patients with and without umbilical discharge. However, the limited statistical power of the study may have influenced the analysis because four out of five patients without suppuration either had symptoms of PSO or had relatives with PSO.

Furthermore, the possibility of a bacterial or fungal infection as the reason behind the umbilical symptoms cannot be ruled out as $42.1 \%(8 / 19)$ of patients had never received topical treatment for their symptoms. In contrast, only 54.5\% (6/11) of those receiving topical treatment found it to be effective. Interestingly, among those that never received treatment for their umbilical symptoms, many mentioned that they had never been asked about umbilical symptoms or mentioned them to their physicians.

\section{References}

1. Jemec GB. Clinical practice. Hidradenitis suppurativa. N Engl J Med. 2012;366: $158-64$.

2. Tzellos T, Zouboulis CC, Gulliver W, Cohen AD, Wolkenstein P, Jemec GB. Cardiovascular disease risk factors in patients with hidradenitis suppurativa: a systematic review and meta-analysis of observational studies. $\mathrm{Br} J$ Dermatol. 2015;173:1142-55.

3. Ring HC, Riis MP, Miller IM, Jenssen H, Fuursted K, Saunte DM, et al. The bacteriology of hidradenitis suppurativa: a systematic review. Exp Dermatol. 2015;24: 727-31.

4. Andersen R, Jemec GB. New treatment strategies for hidradenitis suppurativa. Drugs Today (Barc). 2016;52:439-51.

5. Farzanfar D, Dowlati Y, French LE, Lowes MA, Alavi A. Inflammation: a contributor to depressive comorbidity in inflammatory skin disease. Skin Pharmacol Physiol. 2018;31:246-51.

6. Hamzavi IH, Sundaram M, Nicholson C, Zivkovic M, Parks-Miller A, Lee J, et al. Uncovering burden disparity: a comparative analysis of the impact of moderateto-severe psoriasis and hidradenitis suppurativa. J Am Acad Dermatol. 2017;77: $1038-46$.

7. Hidradenitis suppurativa supportgroup. agonys-plague-the-battle-of-a-lifetimeshavaughns-hidradenitis-suppurativa-patient-story [Internet]. NA: Hidradenitis suppurativa supportgroup; c2017. Available from: https://hidradenitissuppurativasupportgroup.org/hs/agonys-plague-the-battle-of-a-lifetime-shavaughnshidradenitis-suppurativa-patient-story/.
In conclusion, we describe umbilical flares as a possible new sign of HS. This has hitherto not attracted the attention of physicians or patients, as evidenced by the lack of previous reports. A general reply from patients was that many had never considered that their umbilical symptoms could be linked to their HS. Even patients that described their umbilical symptoms with the same terms (mostly suppuration) as their HS lesions had rarely considered it. The authors suggest that UPS may offer a possible explanation for the co-occurrence of this new HS symptom.

\section{Acknowledgement}

The authors would like to thank Bente Villumsen, the president of the Danish HS Association, for conveying our questions to members of the Danish HS Association. We would also like to thank the patient population for their goodwill in answering the questionnaires.

\section{Funding}

This paper received funding from the Leo Foundation. Reference number LF 18002.

\section{Conflicts of interest}

DMS was paid as a consultant for an advisory board meeting by AbbVie, Janssen, Sanofi, and Leo Pharma, and received speaker's honoraria and/or received grants from the following companies during the last 5 years: Bayer, Abbvie, Desitin, Pfizer, Galderma, Astellas, Novartis, and Leo Pharma.

GBEJ has received honoraria from AbbVie, Chemocentryx, Coloplast, Incyte, Inflarx, Novartis, Pierre Fabre, and UCB for participation on advisory boards, grants from Abbvie, Astra-Zeneca, Inflarx, Janssen-Cilag, Leo Pharma, Novartis, Regeneron, and Sanofi for participation as an investigator, and speaker's honoraria from AbbVie, Boehringer-Ingelheim, Galderma, and MSD. He has also received unrestricted departmental grants from Abbvie, Leo Pharma, and Novartis.
8. Lee CC, Lin CH, Yen ZS, Ko PC. An erythematous and draining umbilicus. J Emerg Med. 2006;30:429-31.

9. Rodrigues G. Umbolith: a cause of umbilical discharge and omphalitis. Infection. 2015;43:625.

10. Kaplan M, Kaplan ET, Kaplan T, Kaplan FC. Umbilical pilonidal sinus, an underestimated and little-known clinical entity: report of two cases. Am J Case Rep. 2017;18:267-70.

11. Jackman RJ, McQuarrie HB. Hidradenitis suppurativa: its confusion with pilonidal disease and anal fistula. A J Surg. 1949;77:349-51.

12. Mortimer PS, Dawber RP, Gales MA, Moore RA. Mediation of hidradenitis suppurativa by androgens. Br Med J (Clin Res Ed). 1986;292:245-8.

13. Benhadou F, Van der Zee HH, Pascual JC, Rigopoulos D, Katoulis A, Liakou Al, et al. Pilonidal sinus disease: an intergluteal localization of hidradenitis suppurativa/acne inversa: a cross-sectional study among 2465 patients. $\mathrm{Br} J$ Dermatol. 2019;181:1198-206.

14. Wortsman X, Moreno C, Soto R, Arellano J, Pezo C, Wortsman J. Ultrasound indepth characterization and staging of hidradenitis suppurativa. Dermatol Surg. 2013;39:1835-42. 